\title{
The matching of supply and demand Based on Analytic Hierarchy Process \\ Pinchao Meng ${ }^{1}$,Zhixia Jiang ${ }^{1}$ \\ 1 Department of Applied Mathematics, Changchun University of Science and Technology,
} Changchun, China

\begin{abstract}
This paper adopts the Analytic Hierarchy Process to establish two mathematical models considering three factors, namely "cab service mileage rate ","ten thousand people ownership", "cab turnover per month" : the matching degree of supply and demand for cab of different cities at the same time; the same degree of different times of the matching of supply and demand of the city. Accordingly, we get space and time distribution characteristics of the degree of difficulty to a cab.

Keywords: The matching of supply and demand; Analytic Hierarchy Process; space distribution; temporal distribution

\section{Introduction}

cab is mobile service window of the city, and its service quality affects deeply the passengers' impression for the city[1,2] .We consider three factors, namely "cab service mileage rate ","ten thousand people ownership", "cab turnover per month" ,and adopt the Analytic Hierarchy Process to establish models for analysis of cab supply and demand matching degree. The higher the mileage utilization and vehicle load factors, the easier get a cab;ten thousand people ownership is higher, the easier get a cab too.
\end{abstract}

\section{The models of matching degree of supply and demand}

$\mathrm{Cab}$ ten thousand ownership and taxi month turnover can reflect the status of the development of the taxi industry, if cab ten thousand ownership, the greater the cab resources more abundant; if the taxi turnover, the more the taxi market.It can be seen cab demand situation from the mileage utilization, if the mileage utilization rate is higher, the greater the demand.

Table $1 \mathrm{cab}$ index data

\begin{tabular}{|c|c|c|c|}
\hline City & $\begin{array}{c}\text { Ten thousand people } \\
\text { ownership }\end{array}$ & $\begin{array}{c}\text { Cab turnover per } \\
\text { month(yuan) }\end{array}$ & $\begin{array}{c}\text { Cab service } \\
\text { mileage rate }\end{array}$ \\
\hline Dalian & 36 & 22451.1 & $65.51 \%$ \\
\hline Shenyang & 34 & 22500 & $57.40 \%$ \\
\hline Beijing & 34 & 17205 & $68.00 \%$ \\
\hline Guangzhou & 32 & 27350 & $73.79 \%$ \\
\hline Harbin & 29 & 22500 & $84.10 \%$ \\
\hline Xian & 25 & 19000 & $70.00 \%$ \\
\hline Wuhan & 24 & 21000 & $69.02 \%$ \\
\hline Nanjing & 23.77 & 21094.5 & $65.40 \%$ \\
\hline Chengdu & 23.5 & 23610 & $67.88 \%$ \\
\hline Xiamen & 22.78 & 34211.91 & $72.00 \%$ \\
\hline Qingdao & 22 & 22943 & $64.51 \%$ \\
\hline Ningbo & 20 & 26000 & $68.00 \%$ \\
\hline Hangzhou & 19.6 & 29834 & $69.25 \%$ \\
\hline Jinan & 15.5 & 15000 & $71.70 \%$ \\
\hline Shenzhen & 10.86 & 36636.3 & $69.10 \%$ \\
\hline
\end{tabular}

Data source:CHINA CITY STATISTICAL YEARBOOK 2013 
2.1 The matching degree of supply and demand of different cities at the same time

The matching degree of supply and demand about cab in 15cities of China are set as the target layer and noted as $O$; the three indexes form the criteria layer, noted as $C ; 15$ cities of China are regarded as the scheme layer and noted as $P$, The hierarchical structure is shown in Fig.1.

The target layer $O$

The criteria layer $C$

The scheme layer $P$

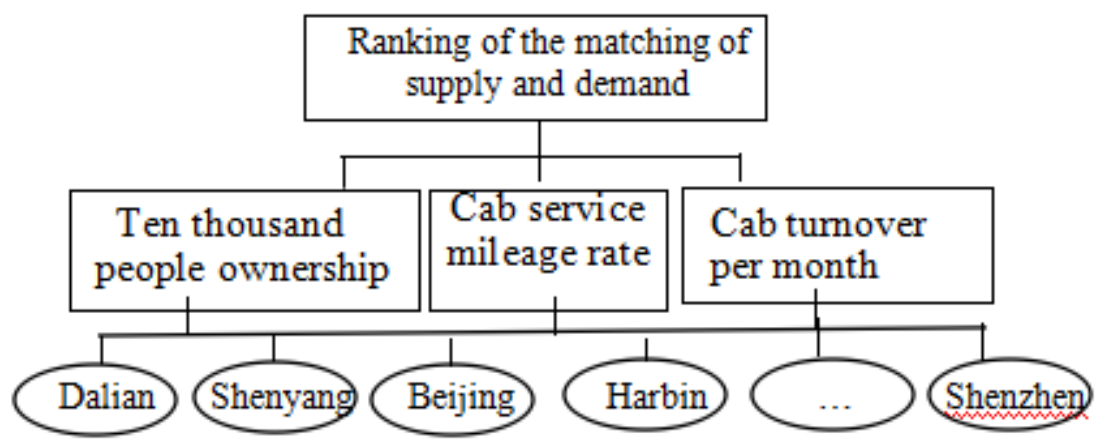

Fig. 1 The hierarchical structure

In the criteria layer, four indexes are ranked from the most important to the least important. Suppose the neighboring two indexes have slight difference in terms of importance. Compare these indexes and get comparison matrix $\mathrm{A}$

$$
A=\left[\begin{array}{ccc}
1 & 2 & 3 \\
\frac{1}{2} & 1 & 2 \\
\frac{1}{3} & \frac{1}{2} & 1
\end{array}\right] .
$$

Define the matching of supply and demand $\omega$ as the difficulty degree for passengers to take a cab .Its computation formula is as follows:

$$
\omega=\omega^{2} \cdot \omega^{1} \text {. }
$$

The maximum eigenvalue and corresponding characteristic vector of $\mathrm{A}$ are calculated as follows[3,4]:

Normalize every column in the judgment matrix of A:

$$
\overline{a_{i j}}=\frac{a_{i j}}{\sum_{k=1}^{n} a_{k j}}, \quad i, j=1,2, \ldots, n .
$$

Add the normalized matrix according to the row

$$
M_{i}=\sum_{j=1}^{n} \overline{a_{i j}}, \quad i=1,2, \ldots, \mathrm{n} .
$$

Normalize vector $M=\left(M_{1}, M_{2}, \cdots, M_{\mathrm{n}}\right)$

$$
W_{i}=\frac{M_{i}}{\sum_{j=1}^{n} M_{j}}, \quad i=1,2, \ldots, \mathrm{n} .
$$

Calculate the maximum characteristic root of judgment matrix of $\mathrm{A}$ 


$$
\lambda_{\max }=\sum_{i=1}^{n} \frac{(A W)_{i}}{n W_{i}}
$$

Where $n=3$.

The maximum eigenvalue is $\lambda_{\text {max }} \approx 3.0092$, and corresponding characteristic vector is:

$$
\omega^{1}=\left[\begin{array}{lll}
0.5390 & 0.2973 & 0.1638
\end{array}\right]^{\mathrm{T}}
$$

According to the consistency index principle $C I_{(1)}=\frac{\lambda_{\max }-n}{n-1}$, the consistency index $\mathrm{CI}(1)$ $=0.0046$; the random consistency index $\operatorname{RI}(1)=0.5200$. The random consistency rate:

$\mathrm{CR}(1)=\mathrm{CI}(1) / \mathrm{RI}(1)=0.0089<0.1$, the judgment matrix has a satisfying consistency.

Table 2 the random consistency index RI

\begin{tabular}{|l|l|l|l|l|l|l|l|l|l|l|l|l|}
\hline $\mathrm{N}$ & 1 & 2 & 3 & 4 & 5 & 6 & 7 & 8 & 9 & 10 & 11 & 12 \\
\hline $\mathrm{RI}$ & 0 & 0 & 0.52 & 0.89 & 1.12 & 1.26 & 1.36 & 1.41 & 1.46 & 1.49 & 1.52 & 1.54 \\
\hline
\end{tabular}

Construct the comparative matrix of scheme layer $\mathrm{P}$ to criteria layer $C_{k}: B_{k}=\left(b_{i j}^{(k)}\right)$. The comparative matrix is the uniform matrix where $\mathrm{b}_{\mathrm{ij}}^{(\mathrm{k})}=\mathrm{T}_{\mathrm{i}}^{(\mathrm{k})} / \mathrm{T}_{\mathrm{j}}^{(\mathrm{k})}$. Thus, the maximum eigenvalue of $B_{k}$ is $\lambda_{\max }^{(k)}=N, C R_{2}^{k}=0$.Any column vector is the characteristic vector of $\lambda_{\max }{ }^{(k)}$.

Suppose $\omega^{\mathrm{k}}=\left(\omega_{1}{ }^{(\mathrm{k})}, \omega_{2}{ }^{(\mathrm{k})}, \ldots, \omega_{\mathrm{N}}{ }^{(\mathrm{k})}\right)^{\mathrm{T}}, \omega^{k}$ is the vector after the weight vector of $C_{k}(\mathrm{k}=1,2,3)$ is weighed and normalized. Note $\omega^{2}=\left(\omega^{(1)}, \omega_{2}{ }^{(2)}, \ldots, \omega_{\mathrm{N}}{ }^{(3)}\right)_{\mathrm{N} \times 3}$, as the weight of P-C. The consistency ratio of $\mathrm{P}-\mathrm{C}$ is $\mathrm{CR}_{(2)}=\sum_{\mathrm{k}=1}^{3} \mathrm{CR}_{2}{ }^{(\mathrm{k})}=0$. The characteristic vector of $\mathrm{P}-\mathrm{C}$ is shown in Table 3.

Table 3 The characteristic vector of P-C

\begin{tabular}{|c|c|c|c|}
\hline$P-C$ & $C_{1}$ & $C_{2}$ & $C_{3}$ \\
\hline Dalian & 0.06325 & 0.09677 & 0.06238 \\
\hline Shenyang & 0.05542 & 0.09140 & 0.06251 \\
\hline Beijing & 0.06566 & 0.09140 & 0.04780 \\
\hline Guangzhou & 0.07125 & 0.08602 & 0.07599 \\
\hline Harbin & 0.08120 & 0.07795 & 0.06251 \\
\hline Xian & 0.06759 & 0.06720 & 0.05279 \\
\hline Wuhan & 0.06664 & 0.06451 & 0.05445 \\
\hline Nanjing & 0.06315 & 0.06390 & 0.05861 \\
\hline Chengdu & 0.06554 & 0.06317 & 0.06560 \\
\hline Xiamen & 0.06952 & 0.06123 & 0.09505 \\
\hline Qingdao & 0.06229 & 0.05914 & 0.06374 \\
\hline Ningbo & 0.06566 & 0.05376 & 0.07224 \\
\hline Hangzhou & 0.06687 & 0.05269 & 0.08289 \\
\hline Jinan & 0.06923 & 0.04167 & 0.04167 \\
\hline Shenzhen & 0.06672 & 0.02919 & 0.10179 \\
\hline
\end{tabular}


The weight vector of scheme layer $\mathrm{P}$ to target layer $\mathrm{C}$ is $\omega^{1}$. So the weight vector of scheme layer $\mathrm{P}$ to criteria layer $\mathrm{O}$ is calculated in the following way:

$$
\omega=\omega^{2} * \omega^{1}=\left(\omega^{(1)}, \omega^{(2)}, \omega^{(3)}\right) * \omega^{1}=\left(\omega_{1}{ }^{(k)}, \omega_{2}{ }^{(k)}, . ., \omega_{n}{ }^{(k)}\right)^{T} .
$$

The consistency ratio index of $\mathrm{P}$ to $\mathrm{O}$ is $: \mathrm{CR}=\mathrm{CR}(2)+\mathrm{CR}(1)=0+0.0089=0.0089<0.1$, which means the comparative matrix has a satisfying consistency and passes the consistency test.Thus, the combination weight $\omega$ can serve as the reference for performance of the matching degree of supply and demand of cab[5]. With the weight considered, the matching degree of 15 cities are shown in Table 4.

Table 4 Ranking of the matching degree

\begin{tabular}{|c|c|c|c|c|c|}
\hline Ranking & City & Result & Ranking & City & Result \\
\hline 1 & Harbin & 0.0772 & 9 & Chengdu & 0.0649 \\
\hline 2 & Guangzhou & 0.0764 & 10 & Wuhan & 0.064 \\
\hline 3 & Dalian & 0.0731 & 11 & Ningbo & 0.0632 \\
\hline 4 & Xiamen & 0.0712 & 12 & Nanjing & 0.0626 \\
\hline 5 & Beijing & 0.0704 & 13 & Qingdao & 0.0616 \\
\hline 6 & Shenyang & 0.0673 & 14 & Shenzhen & 0.0613 \\
\hline 7 & Hangzhou & 0.0653 & 15 & Jinan & 0.0565 \\
\hline 8 & Xian & 0.0651 & & & \\
\hline
\end{tabular}

From Table 4 it is shown that Harbin have the best cab supply matching degree, Jinan is the worst. In general, the higher the mileage utilization, cab supply matching degree is higher. Xiamen is the largest city in ranking changes. If only consider "the cab quantity per ten thousand people ", Xiamen ranked tenth, through analytic hierarchy process, due to a combination of three indicators, it rose by 6 . Sorting result reduced the unfairness caused by single index, to make the result more reasonable.

In table 4 there are eight southern cities and seven northern cities; top 10 cities in north and south city each have five; the northern city accounted for two of the top three; the northern city accounted for two of the last three.In general, the north and the south city ranking distribution is uniform.Visible, at the same time, the cab resources matching degree difference is not obvious in north and south.

\subsection{The same degree of different times of the matching of supply and demand of the city}

This paper has collected Shenzhen $20 \mathrm{cab}$ GPS data.Through GPS records cab longitude and latitude differences of adjacent time, calculate the distance the cab through,Computation formula is as follows:

Distance $=R * \arccos (\sin ($ Lat $A) * \sin ($ Lat $B) * \cos ($ Lon $A-$ LonB $)+\cos ($ Lat $A) * \cos ($ Lat $B)) * P i / 180$

Sum the mileages of cabs that operation status is 0 , we concluded that the total light mileage. Sum the mileages of cabs that operation status is 1, we concluded that the total passenger miles. Note cab mileage utilization=total passenger miles/(total light mileage + the total passenger miles), get average of three statistical indexes each time a day for a cab : 
Table 5 Average of three statistical indexes

\begin{tabular}{|l|l|l|l|l|l|l|l|}
\hline Period & $\begin{array}{l}\text { Cab } \\
\text { service } \\
\text { mileag } \\
\text { e rate }\end{array}$ & $\begin{array}{c}\text { Ten } \\
\text { thousand } \\
\text { people } \\
\text { ownership }\end{array}$ & $\begin{array}{l}\text { Passenger } \\
\text { miles }\end{array}$ & Period & $\begin{array}{l}\text { Cab } \\
\text { service } \\
\text { mileage } \\
\text { rate }\end{array}$ & $\begin{array}{c}\text { Ten } \\
\text { thousand } \\
\text { people } \\
\text { ownership }\end{array}$ & $\begin{array}{l}\text { Passeng } \\
\text { er miles }\end{array}$ \\
\hline 0:00-1:00 & 0.26688 & 10.86 & 3908.3 & $12: 00-13: 00$ & 0.48926 & 10.86 & 10754.2 \\
\hline $1: 00-2: 00$ & 0.53753 & 10.86 & 6073.3 & $13: 00-14: 00$ & 0.78764 & 10.86 & 13718.6 \\
\hline 2:00-3:00 & 0.06447 & 10.86 & 171.1 & $14: 00-15: 00$ & 0.87222 & 10.86 & 15884.3 \\
\hline 3:00-4:00 & 0.47334 & 10.86 & 2967.9 & $15: 00-16: 00$ & 0.72523 & 10.86 & 15489.5 \\
\hline 4:00-5:00 & 0.33123 & 10.86 & 396.2 & $16: 00-17: 00$ & 0.93629 & 10.86 & 14971.1 \\
\hline $5: 00-6: 00$ & 0.53876 & 10.86 & 1440.5 & $17: 00-18: 00$ & 0.82896 & 10.86 & 18342.5 \\
\hline $6: 00-7: 00$ & 0.14197 & 10.86 & 717.9 & $18: 00-19: 00$ & 0.59306 & 10.86 & 7989.9 \\
\hline $7: 00-8: 00$ & 0.73388 & 10.86 & 11356.0 & $19: 00-20: 00$ & 0.58339 & 10.86 & 10153.0 \\
\hline $8: 00-9: 00$ & 0.75889 & 10.86 & 8392.6 & $20: 00-21: 00$ & 0.73594 & 10.86 & 1076.9 \\
\hline $9: 00-10: 00$ & 0.67628 & 10.86 & 15840.5 & $21: 00-22: 00$ & 0.69570 & 10.86 & 8277.1 \\
\hline $10: 00-11: 00$ & 0.80238 & 10.86 & 6989.6 & $22: 00-23: 00$ & 0.43296 & 10.86 & 9249.2 \\
\hline $11: 00-12: 00$ & 0.15070 & 10.86 & 1717.0 & $23: 00-24: 00$ & 0.47692 & 10.86 & 8196.7 \\
\hline
\end{tabular}

Monthly turnover is proportional to the passenger miles cabs, as a result monthly turnover=passenger miles $\times \mathrm{K}(\mathrm{K}$ is constant $)$, month turnover can be replace by passenger miles when we calculate $P-C$ layer vector.

Hierarchical analysis to get degree of difficulty each time period to take a cab :

Table 6 Degree of difficulty to take a cab

\begin{tabular}{|l|l|l|l|}
\hline $0: 00-1: 00$ & 0.0262 & $12: 00-13: 00$ & 0.0408 \\
\hline $1: 00-2: 00$ & 0.0388 & $13: 00-14: 00$ & 0.0551 \\
\hline $2: 00-3: 00$ & 0.0151 & $14: 00-15: 00$ & 0.0603 \\
\hline $3: 00-4: 00$ & 0.0336 & $15: 00-16: 00$ & 0.0541 \\
\hline $4: 00-5: 00$ & 0.0258 & $16: 00-17: 00$ & 0.062 \\
\hline 5:00-6:00 & 0.0349 & $17: 00-18: 00$ & 0.0606 \\
\hline 6:00-7:00 & 0.0186 & $18: 00-19: 00$ & 0.0426 \\
\hline 7:00-8:00 & 0.051 & $19: 00-20: 00$ & 0.044 \\
\hline 8:00-9:00 & 0.0495 & $20: 00-21: 00$ & 0.0424 \\
\hline $9: 00-10: 00$ & 0.0525 & $21: 00-22: 00$ & 0.0469 \\
\hline $10: 00-11: 00$ & 0.05 & $22: 00-23: 00$ & 0.0373 \\
\hline $11: 00-12: 00$ & 0.0198 & $23: 00-24: 00$ & 0.0382 \\
\hline
\end{tabular}

Table 6 shows that period of the most likely to take a cab are 8:00-11:00 and 14:00-18:00, the worst period to take a cab are 2:00-3:00, 6:00-8:00 and 11:00-12:00. The reason for 2:00-3:00 is that less operating cab of this period, and probably distance too far away from the passengers; the reason for 6:00-8:00 is that demand is the point of time to work or school and cab is not entirely to the post; The reason for 11:00-12:00 is from work or school at the peak of the sudden increase demand, presents the phenomenon which is in short supply. 


\section{Summary}

City cab service quality not only play a crucial role to promote the city's economic and social development, and can improve the city residents lives easier and reputation, improve the image of the city[6]. But because of the influence of a variety of reasons, the difficulty of taking a cab caused so much inconvenience to people's travel. This paper studies the different difficulty level by the status quo, in order to further provide theoretical basis for improve the quality of cab services.

\section{References}

[1]KI Wong, SC Wong, H Yang, JH Wu, Modeling urban taxi services with multiple user classes and vehicle modes[J],Transportation Research Part B Methodological, 2008, 42(10):985-1007

[2]H Yang, M Ye, W Tang, S Wong,Multi-period dynamic modeling of urban taxi services[J]. Proceedings of the Seventh Conference of Hong Kong Society for Transportation Studies. 2002: 310-319

[3]J. M. Hummel, S. W. F. Omta, W. Rossum, G. J. Verkerke, G. Rakhorst.The analytic hierarchy process: An effective tool for a strategic decision of a multidisciplinary research center[J]. Knowledge, Technology \& Policy, 1998, 11 (1): 41-63

[4]Mohammad Sadegh Pakkar,An integrated approach based on DEA and AHP[J].Computational Management Science, 2015, 12 (1):153-169

[5]Srihari Jaganathan, Jinson J. Erinjeri, Jun-ing Ker. Fuzzy analytic hierarchy process based group decision support system to select and evaluate new manufacturing technologies[J]. The International Journal of Advanced Manufacturing Technology, 2007, 32 (11):1253-1262

[6]T Yang, H Yang, SC Wong, Taxi services with search frictions and congestion externalities[J]. Journal of Advanced Transportation, 2014, 48(6):575-587 